Check for updates

Cite this: RSC Adv., 2017, 7, 50367

Received 2nd October 2017

Accepted 19th October 2017

DOI: 10.1039/c7ra10899k

rsc.li/rsc-advances

\section{Synthesis of tetrazole fused azepanes and quantum chemical topology study on the mechanism of the intramolecular cycloaddition reaction $\dagger$}

\author{
M. S. Pino-Gonzalez, (D) ${ }^{* a}$ A. Romero-Carrasco, (D) ${ }^{a}$ S. Calvo-Losada, (D) *b N. Oña- \\ Bernal, (D) ${ }^{a}$ J. J. Quirante (iD ${ }^{b}$ and F. Sarabia (D) ${ }^{a}$
}

\begin{abstract}
The synthesis of novel tetrazolo azepanes from azido nitriles by 1,3 intramolecular dipolar cycloaddition starting from monosaccharide derivatives is described. A quantum chemical topological study on the intramolecular cyclization process has been conducted rendering a pseudo-concerted mechanism. Conformational study was done for the final products which showed a preferential twist boat conformation, theoretically suitable for mannosidase inhibition. However, the tetrazoles showed no significant inhibition of glycosidases.
\end{abstract}

Nitrogen-containing sugar analogues, known as iminosugars ${ }^{1}$ have attracted considerable attention from synthetic and medicinal chemists, biologists, and clinical researchers by their potential ability to inhibit glycosidases and glycosyl transferases. Most of works on the design and synthesis of glycosidase inhibitors have focused on five- and six-membered iminosugars, which are considered to mimic the substrate transition states. However, the greater flexibility of seven-membered ring should increase the binding to the active site of the enzyme. More potent analogues and derivatives could possibly be obtained by structural changes of the polyhydroxyazepanes described to date. ${ }^{2}$ On the other hand, the discovery of the natural nagstatin, ${ }^{3}$ potent inhibitor of hexosaminidases, and the search of mimetics of glycono lactones, ${ }^{4 a-c}$ known by their inhibitory activities, prompted a great deal of interest and a number of bicyclic azoles derived from carbohydrates were synthesized by different research groups. ${ }^{3 c, 8}$ The often higher biochemical activity displayed by these bicyclic heterocycles, ${ }^{5 \boldsymbol{b}}$ in comparison with monocyclic analogues, has been attributed to their greater rigidity; the polyhydroxylated moiety being effectively locked in a conformation favouring inhibition. ${ }^{5 b}$ Most of these compounds are imidazoles, ${ }^{4 a, 4 d, 6}$ triazoles $^{3 c, 4 a, 4 b, 8}$ and tetrazoles, ${ }^{4 a, 4 b, 5,7,9 a}$ fused to hydroxylated piperidines and pyrrolidines. The glycosidase inhibition results studied by Vasella and Heightman ${ }^{4 a}$ showed the tetrazole pyrimidines 1-4 to be an imperfect transition state analogue (Fig. 1). Besides, the tetrazole $\mathbf{1}$ and the triazole 6 are glycogen phosphorylase inhibitors. Recently, ${ }^{\mathbf{b}}$ glucoimidazole $\mathbf{5}$

${ }^{a}$ Department of Organic Chemistry, Faculty of Sciences, University of Málaga, Spain. E-mail:pino@uma.es

${ }^{b}$ Department of Physical Chemistry, Faculty of Sciences, University of Málaga, Spain. E-mail: asenruhup@hotmail.com

$\dagger$ Electronic supplementary information (ESI) available. See DOI: 10.1039/c7ra10899k has been used in studies related to Gaucher disease. The tetrazolo pyrrolidines 7, 8 (ref. 5) and $\mathbf{8}\left(\right.$ ent) ${ }^{5}$ are glycosidase inhibitors. As far as we are aware, in the literature there are only a few azoles fused to polyhydroxylated seven member rings: triazole $\mathbf{9}$ (ref. 10) and tetrazoles $\mathbf{1 0 .}{ }^{11}$ Triazole $\mathbf{9}$ was found to be a very weak inhibitor of $E$. coli $\alpha$-galactosidase and of isomaltase ( $\alpha$-glucosidase). ${ }^{10}$ All these facts have stimulated our interest in synthesizing new bicyclic azoles like 13 and $\mathbf{1 4}$ in which the rigidity of the aromatic azole could compensate the possibly excessive flexibility of the monocyclic polyhydroxylated azepanes $\mathbf{1 1}$ and $\mathbf{1 2}$ (ref. 12) and improve their behaviour as glycosidase inhibitors (Fig. 1).
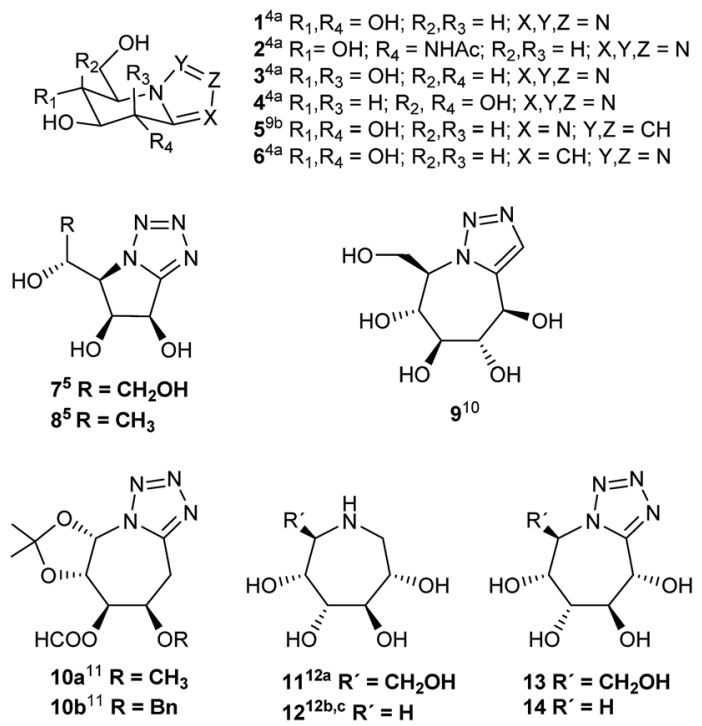

Fig. 1 Fused azolo derivatives and azepanes synthesized from monosaccharides. 
The mechanism of tetrazole formation by addition of azide to nitriles has been well studied. ${ }^{13}$ Nonetheless, there are scant studies on the mechanism of this reaction when azido and nitrile group are in the same molecule to yield a bicyclic compound. ${ }^{14}$ To the best of our knowledge, there are no mechanistic studies based on the formation of tetrazolo fused to seven-membered rings.

With this in mind and with the aim of obtaining new and more powerful analogues, we have attained the formation of tetrazolic systems fused to a seven-membered ring starting from monosaccharide derivatives. Firstly, the azido alcohol 15 obtained regioselectively in previous experiences ${ }^{\mathbf{1 5}}$ from epoxyamides was chosen (Scheme 1). Benzylation of diol 15 and further acetal deprotection to $\mathbf{1 7}$ allowed us to obtain the azido amide 18, formed in the oxidant conditions provided by iodine in aqueous ammonia. Direct conversion of hemiacetal 17 into the nitrile, following Fang's conditions, ${ }^{\mathbf{1 6}}$ was tried, but amide 18 was obtained as major product (81\%), with a rest of nitrile 19. Dehydration of the amide to nitrile 21 was successful with the acetylated azido-amide $\mathbf{2 0}$. With the nitrile $\mathbf{2 1}$ in hands we had the desired functionalization to accomplish the cyclization to the bicyclic compounds. Cycloaddition $[3+2]$ by heating in dimethyl sulfoxide led to the protected tetrazolo azepane $\mathbf{2 2}$. Deacetylation and subsequent hydrogenation gave the tetrazolo pentahydroxy azepane 13. NMR data (with H-MQC and COSY) of tetrazoles 22, 23 and $\mathbf{1 3}$ let us the structural elucidation for this type of compounds.

With the purpose of extending the methodology starting from more accesible monosaccharide derivatives, we followed the same strategy with the monotosylated 24 obtained from Dglucose (Scheme 2). Displacement of the tosylate group by sodium azide and further benzylation gave azide 26a. Acetal hydrolysis of the dibenzylated 26a and subsequent treatment with iodine in aqueous ammonia gave, analogously as for
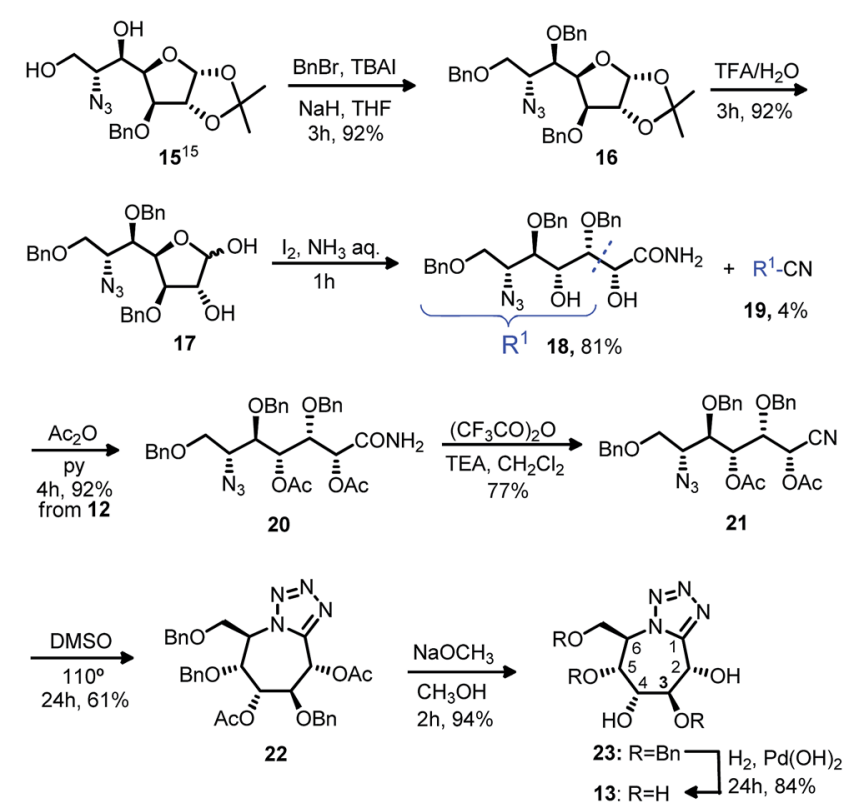

Scheme 1 Synthesis of tetrazolo pentahydroxyazepanes.
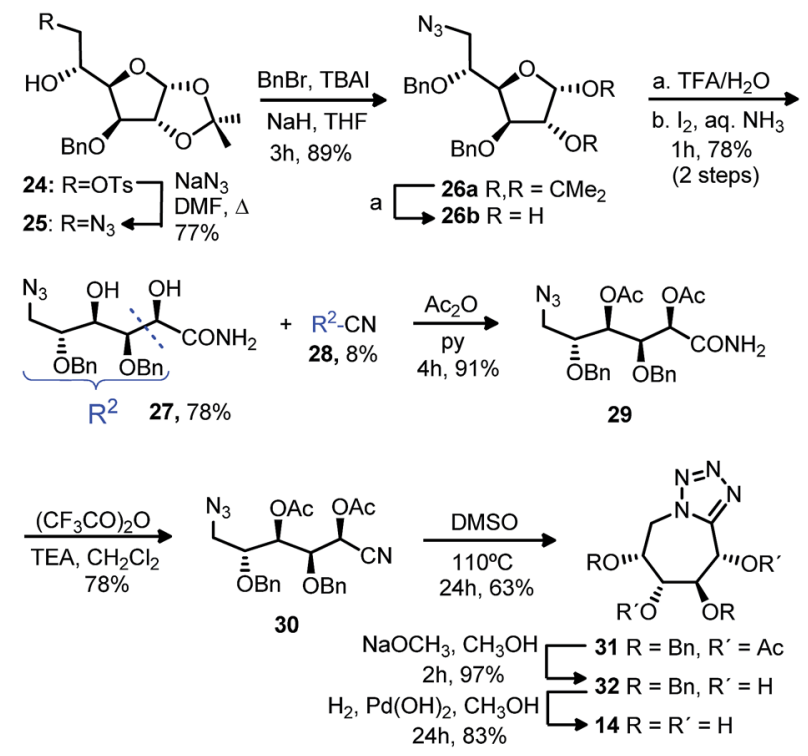

Scheme 2 Synthesis of tetrazolo tetrahydroxyazepanes.

compound 18, azidoamide 27 as major product (78\%). The diacetylated $\mathbf{2 9}$ formed from acetylation of compound $\mathbf{2 7}$ was treated with trifluoroacetic anhydride and triethyl amine to obtain the desired cyano derivative 30. Cyclization to the bicyclic compound $\mathbf{3 1}$ was carried out in similar conditions as for the analogous 22. Deacetylation followed by debenzylation gave the tetrazol tetrahydroxyazepane 14 .

Minor products 19 or 28 , in $4 \%$ or $8 \%$ yield, were isolated in the reactions to amides 18 or 27 , respectively. NMR data of compounds 19 and 28 corresponded to degradated nitriles with one atom of carbon less.

\section{Computational study}

Conformational studies were carried out to compare the preferred conformation of the new compounds with that of other known related compounds and look for a structurereactivity relationship as potential glycosidase inhibitors. Firstly, the configurational assignment for the new azepanes $\mathbf{1 3}$ and 14 had been verified with the experimental coupling constants values $(J)$ obtained from ${ }^{1} \mathrm{H}$ NMR spectra $\left(\mathrm{CDCl}_{3}, 400\right.$ MHz). Thus, $J_{2,3}$ and $J_{3,4}$ values showed a proton trans-relationship, while $J_{4,5}$ gave a cis-relationship as expected (Table 1). For each conformer the coupling constants were calculated according to the method of Kutateladze and Hornback. ${ }^{17}$ The

Table 1 Experimental and estimated coupling constants $\mathrm{J}(\mathrm{Hz})$ for compounds 13 and 14

\begin{tabular}{lrrrrrrr}
\hline & \multicolumn{3}{c}{$\mathbf{1 3}$} & & & \multicolumn{3}{c}{$\mathbf{1 4}$} \\
\cline { 2 - 3 } \cline { 6 - 7 }$J(\mathrm{~Hz})$ & $J_{2,3}$ & $J_{3,4}$ & $J_{4,5}$ & & $J_{2,3}$ & $J_{3,4}$ & $J_{4,5}$ \\
\hline Exp. & 9.7 & 8.6 & 2.0 & & 9.1 & 9.1 & 2.2 \\
Theor. & 10.2 & 8.2 & 3.9 & & 9.7 & 9.5 & 4.9
\end{tabular}




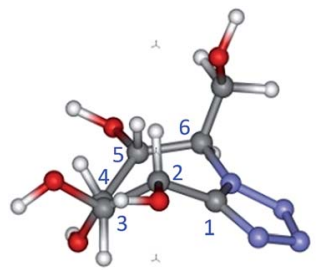

13

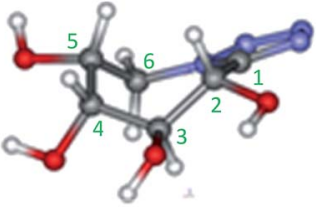

14
Fig. 2 Compounds 13 and 14

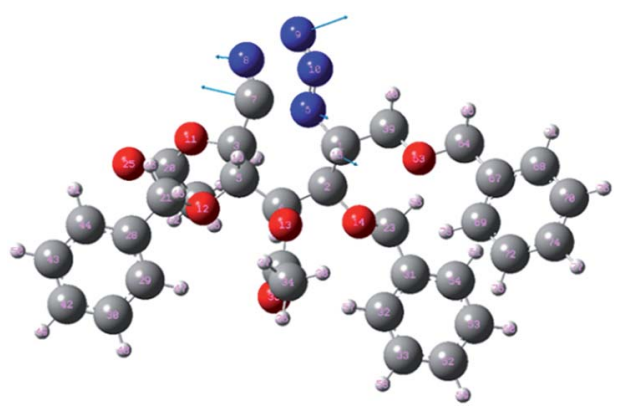

Fig. 3 Transition state for the cyclization reaction of 21 to 22. Arrows show the atomic components of the transition vector with an imaginary frequency of $477,00 \mathrm{i} \mathrm{cm}{ }^{-1}$.

results were compared with the experimentally determined values (NMR). The conformers which fitted better the experimental values are those depicted in Fig. 2. These conformers of $\mathbf{1 3}$ and $\mathbf{1 4}$ showed a twist boat conformation that is theoretically suitable for mannosidase inhibition. ${ }^{4 e, 18}$

In order to get insight into the reaction mechanism, the experimental results were coupled with theoretical calculations at the DFT level and quantum theory atom-in-molecules (QTAIM) analysis. This methodology has been successfully applied by us in previous studies on cyclization to triazoles. ${ }^{19}$ Computations were carried out with G09 and G09w suites of programs $^{20,21}$ by using the hybrid-long range-CGA density functional LC-wPBE in combination with the Pople's 6-31G(d), $6-31+G(d)$, and $6-311++G(d, p)$ basis sets. Solvent effects were

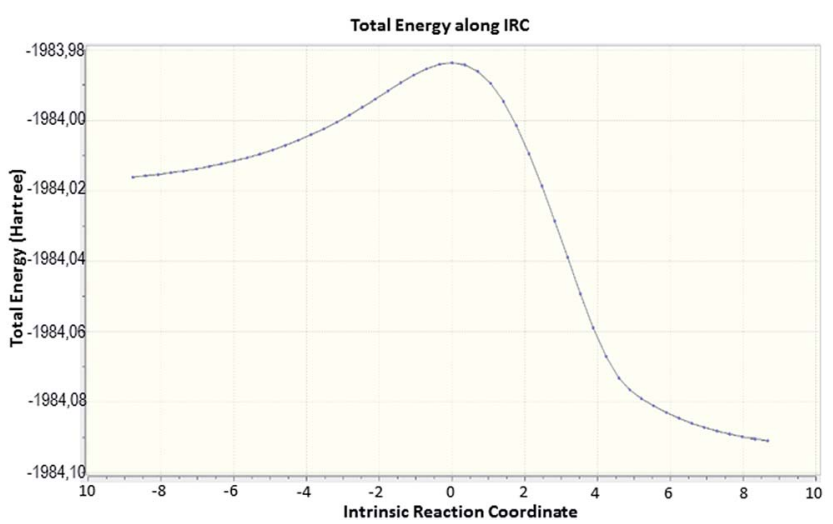

Fig. 4 Reaction energy profile for the cyclization of 21 to 22.

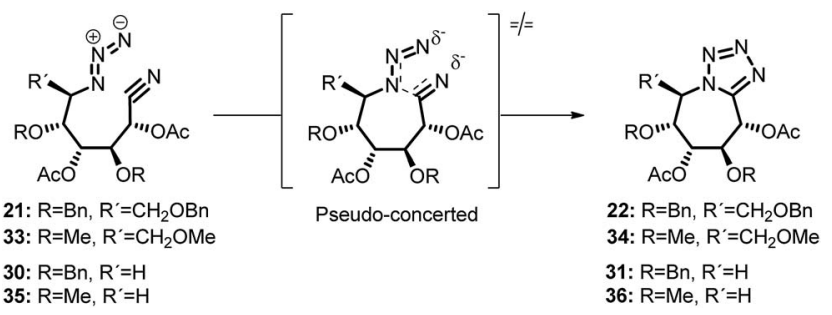

Scheme 3 Cyclizations to bicyclic compounds 22, 34, 31 and 36.

introduced in calculations by means of the PCM method developed by Tomasi et al., ${ }^{21 b}$ as it is implemented in G09, taking the DMSO as solvent. Full optimizations were performed with the analytic Hessian recomputed at every optimization step at the LC-wPBE(DMSO)/6-31G(d) level. The transition structures (TSs) were confirmed by frequency calculations and subsequent IRC (Intrinsic Reaction Coordinate) calculations. ${ }^{21 a}$ At selected stationary points along the IRC, the LC-wPBE(DMSO)/6$311++\mathrm{G}(\mathrm{d}, \mathrm{p}) / / \mathrm{LC}-\mathrm{wPBE}(\mathrm{DMSO}) / 6-31 \mathrm{G}(\mathrm{d})$ electronic charge density was studied by exploring the topologies of the proper $\rho(r)$ function and the one of its associated Laplacian scalar field, $\nabla^{2} \rho(r)$, by using the AIM2000-2.0 software. ${ }^{22 a}$

In general, secondary interactions can be crucial in the course of many chemical reactions. The study of Critical Points (CPs) of $\rho(r)$ and the trajectories of $\nabla \rho(r)$ should allow us to properly characterize them by the existence of both topological elements, $(3,-1)$ Bond Critical Point (BCP) and the two bond paths connecting the BCP with the corresponding pair of atoms. ${ }^{22 b}$ In the BCP notation, the first number, or rank, standing for the number of nonzero curvatures of the function and the second one the corresponding sum of signs, or signature. It is well stated that secondary contacts are closed-shells interactions characterized by a combination of low charge density at the $(3,-1)$ BCP with a negative and also low value of $L$ $=-\nabla^{2} \rho(r){ }^{23}$ Fig. 3 shows the transition state for the intramolecular cyclization of $\mathbf{2 1}$ and its transition vector towards the reactive valley, and Fig. 4 the corresponding energy profile.

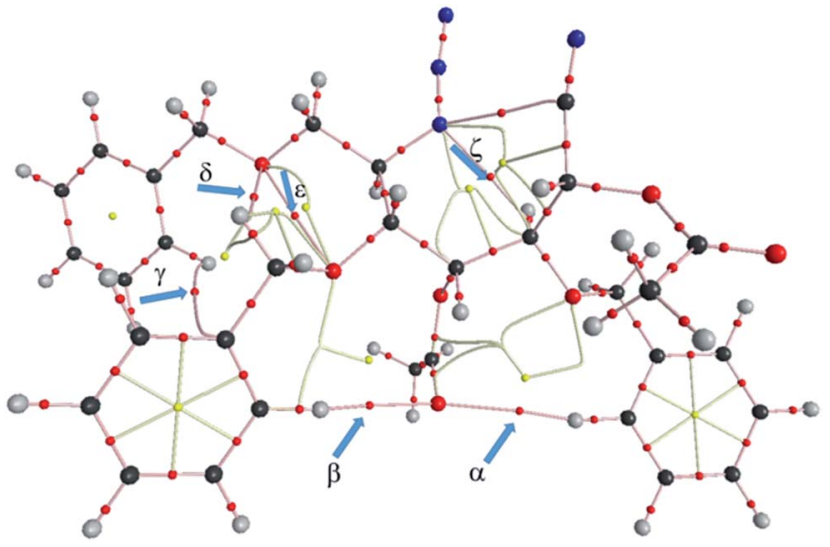

Fig. 5 The computed LC-wPBE(DMSO)/6-311++G(d,p)//LCWPBE(DMSO)/6-31G(d) molecular graph. Relevant closed-shell interactions have been indicated with blue arrows. 
The LC-wPBE(DMSO)/6-31G(d) activation energy barrier for the cycloaddition of the benzyloxy derivative 21 leading 22, taken from the corresponding minimum, was $28.74 \mathrm{kcal} \mathrm{mol}^{-1}$. It was $28.96 \mathrm{kcal} \mathrm{mol}^{-1}$ in the case of trimethoxy derivative analogues 33 , to form 34 , or $26.83 \mathrm{kcal} \mathrm{mol}^{-1}$ for the cyclization of 35 to 36, in this case with two methoxy groups instead, (Scheme 3 and ESI $\dagger$ ). ${ }^{24}$ The transition state turns out to be energetically favoured with the three benzyloxy protective groups, because of two of these groups, the ones attached to C2 and C5, fix a favourable conformation for the intramolecular cycloaddition reaction. In effect, the molecular graph obtained from the AIM analysis of the electronic density at LCwPBE(DMSO)/6-311++G(d,p)//LC-wPBE(DMSO)/6-31G(d) reveals a non-negligible number of closed-shell secondary interactions in that transition state, some of them of H-type character (see characterization in ESI $\dagger$ ). The formation of the azepane ring is accomplished prior to the second cyclization to give the tetrazolo azepane (observe the formation of the $\mathrm{N}-\mathrm{C}$ bond before the $\mathrm{N}-\mathrm{N}$ one in Fig. 3 and 5). That is to say, our results reveal a pseudo-concerted mechanism, having an early formation of the new $\mathrm{C}-\mathrm{N}$ bond.

\section{Glycosidase inhibition tests}

The inhibitory activities of the tetrazoles $\mathbf{1 3}$ and $\mathbf{1 4}$ were examined against eleven glycosidases (see ESI $\dagger$ ). Only a very weak inhibition was observed for $\beta$-galactosidase from Aspergillus ory$z a e(16 \%$ at $1 \mathrm{mM})$ with the compound 14 ; and for $\beta$-D-glucosidase from almonds ( $38 \%$ at $1 \mathrm{mM}$ ) with the hydroxymethyl analogue 13. It can be concluded that contrary to our initial hopes, the tetrazole system does not enhance the glycosidase inhibitory activity, in comparison with the inhibition showed by monocyclic polyhydroxylated azepanes with the same configuration 11 (ref. $12 a$ ) and 12 (ref. $12 b$ and $c$ ); or the triazole analogous $10{ }^{10}$ Thus, compound 11 was reported to inhibit the enzymes $\beta$-glucosidase $(\mathrm{IC} 50=21.6 \mathrm{mM})$ and $\beta$-galactosidase $($ IC50 $=44.3 \mathrm{mM}) \cdot{ }^{12 a}$ Analogously, compound 12 showed inhibition for the enzymes $\alpha$ galactosidase from green coffee beans $(87 \%)$ and $\alpha$-fucosidase from bovine kidney (95\%) at $120 \mu \mathrm{M} .{ }^{12 b, c}$ The obtained results are not in correlation with the published properties of the azolo piperidine family, where tetrazole enhanced the glycosidase inhibition activity. ${ }^{4 a}$ In order to obtain analogues with positive inhibition against glycosidases, these synthetic strategies are being applied to other monosaccharides. Moreover, the features of these compounds could be suitable for other biological targets. The possibility of increasing biological activity with different fused azole rings will be tested.

In conclusion, we have achieved efficiently the syntheses of the fused tetrazolo azepanes $\mathbf{1 3}$ and $\mathbf{1 4}$ from azido nitriles obtained from carbohydrate derivatives. Unfortunately, glycosidase inhibition tests of the new compounds showed very weak results. However the preferred calculated conformations for these compounds 13 and 14 were suitable for an inhibition pattern. Computational mechanistic study of the cyclization process has been carried out showing a pseudo-concerted mechanism.

\section{Conflicts of interest}

There are no conflicts to declare.

\section{Acknowledgements}

This work was financially supported by Ministerio de Economía y Competitividad (MINECO) (CTQ2014-60223-R) and Consejería de Educación y Ciencia of Junta de Andalucía (FQM-0158). The authors thank the collaboration of Dr I. Robina group, University of Seville, in inhibition tests. S. C. L. and J. J. Q thanks for generous allocation time at Picasso Supercomputer and Rafael Larrosa for his assistance.

\section{Notes and references}

1 (a) Iminosugars: From synthesis to Therapeutic Applications, ed. P. Compain and O. R. Martin, John Wiley \& Sons, New York, 2007; (b) Iminosugars as Glycosidase Inhibitors: Nojirimycin and Beyond, ed. A. E. Stütz, Wiley-VCH, Weinheim, Germany, 1999; (c) B. G. Winchester, Tetrahedron: Asymmetry, 2009, 20, 645.

2 (a) Review: S. Pino-González, C. Assiego and N. Oñas, Targets Heterocycl. Syst., 2004, 8, 364; (b) H. Li, C. Schütz, S. Favre, Y. Zhang, P. Vogel and Y. Blériot, Org. Biomol. Chem., 2006, 4, 1653; (c) N. Oña, A. Romero, C. Assiego, C. Bello, P. Vogel and M. S. Pino-González, Tetrahedron: Asymmetry, 2010, 21, 2092; (d) J. Deschamp, M. Mondon, S. Nakagawa, A. Kato, D. S. Alonzi, T. D. Butters, Y. Zhang, M. Sollogoub and Y. Blériot, Bioorg. Med. Chem., 2012, 20, 641; (e) M. A. González-Castro, D. L. Poole, J. C. Estévez, G. W. J. Fleet and R. J. Estévez, Tetrahedron: Asymmetry, 2015, 26, 320; (f) H. Taghzouti, S. Goumain, D. Harakat, C. Portella, J.-B. Behr and R. Plantier-Royon, Bioorg. Chem., 2015, 58, 11.

3 (a) T. Aoyama, H. Naganawa, H. Suda, K. Uotani, T. Aoyagi and T. Takeuchi, J. Antibiot., 1992, 45, 1557; (b) K. Tatsuta and S. Miura, Tetrahedron Lett., 1995, 36, 6721; (c) K. Tatsuta, Y. Ikeda and S. Miura, J. Antibiot., 1996, 49, 836. 4 (a) T. D. Heightman and A. T. Vasella, Angew. Chem., Int. Ed., 1999, 38, 750, and references therein; (b) N. Panday, M. Meyyappan and A. Vasella, Helv. Chim. Acta, 2000, 83, 513; (c) J. Pabba and A. Vasella, Helv. Chim. Acta, 2006, 89, 2006; (d) J. Pabba, B. P. Rempel, S. G. Withers and A. Vasella, Helv. Chim. Acta, 2006, 89, 635; (e) L. E. Tailford, W. A. Offen, N. L. Smith, C. Dumon, C. Morland, J. Gratien, M.-P. Heck, R. V. Stick, Y. Bleriot and A. Vasella, Nat. Chem. Biol., 2008, 4, 306-312.

5 (a) B. G. Davis, R. J. Nash, A. A. Watson, C. Smith and G. W. J. Fleet, Tetrahedron, 1999, 55, 4501; (b) B. Davis, T. W. Btandstetter, L. Hackett, B. G. Winchester, R. H. Nash, A. Watson, R. Griffiths, C. Smith and G. W. J. Fleet, Tetrahedron, 1999, 55, 4489, and references therein.

6 D. Deredas, M. Skowron, E. Salomon, C. Tarnus, T. Tschamber, W. M. Wolf and A. Frankowski, Tetrahedron, 2007, 63, 2915. 
7 For tetrazolo non-fused pyrrolidines see: P. Chen, M. Gao, D.-X. Wang, L. Zhao and M.-X. Wang, Chem. Commun., 2012, 48, 3482.

8 (a) M. L. Mitchell, F. Tian, L. V. Leeand and C.-H. Wong, Angew. Chem., Int. Ed., 2002, 41, 3041; (b) J. MarcoContelles and M. Rodríguez-Fernández, Tetrahedron Lett., 2000, 41, 381; (c) S. R. Putapatri, A. Kanwal, B. Sridhar, S. K. Banerjee and S. Kantevari, Org. Biomol. Chem., 2014, 12, 8415.

9 (a) T. M. Gloster, P. Meloncelli, R. V. Stick, D. Zechel, A. Vasella and G. J. Davies, J. Am. Chem. Soc., 2007, 129, 2345; (b) R. Charoenwattanasatien, S. Pengthaisong, I. Breen, R. Mutoh, S. Sansenya, Y. Hua, A. Tankrathok, L. Wu, Ch. Songsiriritthigul, H. Tanaka, S. J. Williams, G. J. Davies, G. Kurisu and J. R. Ketudat Cairns, ACS Chem. Biol., 2016, 11, 1891.

10 K. Tezuka, P. Compain and O. R. Martin, Synlett, 2000, 12, 1837.

11 N. R. Paz, A. G. Santana, C. G. Francisco, E. Suarez and C. C. Gonzalez, Org. Lett., 2012, 14, 3388.

12 (a) S. D. Markad, N. S. Karanjule, T. Sharma, S. G. Sabharwal and D. D. Dhavale, Org. Biomol. Chem., 2006, 4, 3675; (b) F. Moris-Varas, X.-H. Qian and C.-H. Wong, J. Am. Chem. Soc., 1996, 118, 7647; (c) N. B. Kalamkar, V. M. Kasture, S. T. Chavan, S. G. Sabharwal and D. D. Dhavale, Tetrahedron, 2010, 66, 8522.

13 F. Himo, Z. P. Demko, L. Noodleman and K. B. Sharpless, J. Am. Chem. Soc., 2002, 124, 12210.

14 F. Himo, Z. P. Demko and L. Noodleman, J. Org. Chem., 2003, 68, 9076.

15 N. Oña, A. Romero-Carrasco and M. S. Pino-González, Tetrahedron: Asymmetry, 2013, 24, 156.

16 S. Talukdar, J.-L. Hsu, T.-Ch. Chou and J.-M. Fang, Tetrahedron Lett., 2001, 42, 1103.

17 A. G. Kutateladze and J. M. Hornback, J. Chem. Educ., 2001, 78, 81 .
18 M. M. Palcic, Nat. Chem. Biol., 2008, 4, 269.

19 (a) S. Calvo-Losada, M. S. Pino-Gonzalez and J. J. Quirante, J. Phys. Chem. B, 2015, 119, 1243; (b) S. Calvo-Losada, M. S. Pino and J. J. Quirante, J. Mol. Model., 2014, 20, 2187. 20 (a) M. J. Frisch, G. W. Trucks, H. B. Schlegel, G. E. Scuseria, M. A. Robb, J. R. Cheeseman, G. Scalmani, V. Barone, B. Mennucci, G. A. Petersson, H. Nakatsuji, M. Caricato, X. Li, H. P. Hratchian, A. F. Izmaylov, J. Bloino, G. Zheng, J. L. Sonnenberg, M. Hada, M. Ehara, K. Toyota, R. Fukuda, J. Hasegawa, M. Ishida, T. Nakajima, Y. Honda, O. Kitao, H. Nakai, T. Vreven, J. A. Montgomery Jr, J. E. Peralta, F. Ogliaro, M. Bearpark, J. J. Heyd, E. Brothers, K. N. Kudin, V. N. Staroverov, T. Keith, R. Kobayashi, J. Normand, K. Raghavachari, A. Rendell, J. C. Burant, S. S. Iyengar, J. Tomasi, M. Cossi, N. Rega, J. M. Millam, M. Klene, J. E. Knox, J. B. Cross, V. Bakken, C. Adamo, J. Jaramillo, R. Gomperts, R. E. Stratmann, O. Yazyev, A. J. Austin, R. Cammi, C. Pomelli, J. W. Ochterski, R. L. Martin, K. Morokuma, V. G. Zakrzewski, G. A. Voth, P. Salvador, J. J. Dannenberg, S. Dapprich, A. D. Daniels, O. Farkas, J. B. Foresman, J. V. Ortiz and J. Cioslowski, Gaussian 09 Revision B.01 M., and Revision A.02 SMP J., Gaussian, Inc., Wallingford, CT, 2010; (b) R. D. Dennington II, T. A. Keith, and J. Millam, Gaussview 5.0.8, Gaussian, Inc., Wallingford, CT, 2008.

21 (a) P. Hratchian and H. B. Schlegel, J. Chem. Theory Comput., 2005, 1, 61; (b) J. Tomasi, B. Mennucci and R. Cammi, Chem. Rev., 2005, 105, 2999.

22 (a) F. Biegler-Koning and J. Schönbohm, J. Comput. Chem., 2002, 23, 1489; (b) R. F. W. Bader, J. Phys. Chem. A, 1998, $102,7314$.

23 P. L. A. Popelier, Atoms in Molecules. An Introduction, Pearson Education. Harlow, UK, 2000.

24 Initial calculations were carried out with methyl groups as substituents due to their minor complexity. 